\title{
Set Aside when Building the Periodic Table 150 Years ago, are Rare Earths any better considered by Chemists in the $21^{\text {st }}$ Century?
}

\author{
Claude Piguet*
}

\begin{abstract}
A hundred and fifty years ago, the Rare Earths posed a serious problem to Mendeleyev because of their very similar chemical properties, although their atomic mass dispersions pointed to different elements. This difficulty persisted for several decades and only the emergence of the atomic theory provided some legitimacy for their consideration as a full series of 15 elements resulting from the filling of the $4 f$ orbitals $\left(L a-4 f^{0}\right.$ to $\left.\mathrm{Lu}-4 \mathrm{f}^{14}\right)$, to which scandium and yttrium were added for the sake of chemical similarities. However, it is difficult to give up bad habits and major advances in transition metal chemistry started systematically with d-block cations prior to extension to f-block analogues, and this despite the broader perspectives often brought by the latter. The technology-oriented society put in place for economic reasons during the last five decades has reactivated scientific interest in the Rare Earths, which have now become essential for many applications in telecommunications, lasers, magnetic materials and optical devices.
\end{abstract}

Keywords: 4f-subshell · Luminescence · Magnetism · Rare Earths

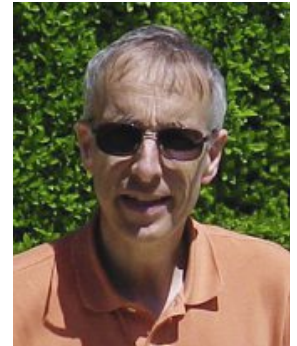

Claude Piguet earned a $\mathrm{PhD}$ degree in 1989 in the field of biomimetic copper-dioxygen complexes under the supervision of Prof. A. F. Williams. After postdoctoral periods in the groups of professors J.-M. Lehn and J.-C. G. Bünzli, he started research projects in the field of lanthanide supramolecular chemistry. He received the Werner Medal of the New Swiss Chemical Society (1995) and was appointed as a full professor of inorganic chemistry at the University of Geneva (1999). He has co-authored more than 200 scientific articles addressing various aspects of basic chemistry and physics. In 2009, he was awarded the Lecoq de Boisbaudran Senior Award from the European Rare Earth Society. Since 2010 he has been teaching Lanthanide Chemistry at the Ecole Normale Supérieure (Paris).

\section{Introduction}

The term 'Rare Earths' seems to be ambiguous for modern chemists because they refer, on one hand, to what Greek philosophers named the elements (earth, air, fire and water) as components of the world and, on the other hand, to something strange, precious and unusual (rare). In reality, the Rare Earths correspond to the lanthanide elements ( $\mathrm{Ln}: \mathrm{La}-\mathrm{Lu} ; Z=57-71)$ together with their analogues from the previous periods, scandium for period 4 and yttrium for period 5 (Fig. 1a). They are not 'rare' in the earth's crust with abundancies between those of copper and silver (Fig. 1b). Moreover, two centuries after the discovery of the first member of the series, yttrium, in 1794 by the Finnish chemist Johan Gadolin, and 70 years after the characterization of the last non-synthetic element of the periodic table, promethium, also a Rare Earth, the chemical and physical properties of these elements

${ }^{*}$ Correspondence: Prof. Dr C. Piguet

E-mail: Claude.Piguet@unige.ch

Department of Inorganic and Analytical Chemistry, University of Geneva

30 quai E. Ansermet, $\mathrm{CH}-1211$ Geneva 4 probably hold no more surprises for modern chemists. Extensive and tutorial reviews on their discovery, ${ }^{[1]}$ properties ${ }^{[2]}$ and applications ${ }^{[3]}$ are commonly available. In order to keep the corpus of Rare Earth knowledge intact and to transmit it to following generations, the Rare Earth community regularly, since 1978, solicits recognized specialists to review their fields in tutorial review papers, which are bound in volumes, sometimes with a theme. The first volume of the 'Handbook on the Physics and Chemistry of Rare Earth' appeared in 1978 and, since then, 53 volumes and 302 chapters have been published. ${ }^{[4]}$ This short contribution has therefore no intention of giving a comprehensive overview of the topics, but only to highlight with a minimum of bias what the author believes to be the most important steps which transformed the Rare Earths, judged unsuitable by Mendeleyev for inclusion in the periodic table in 1869 , into full members with many applications in modern technologies.

\section{Rare Earths in the Periodic Table: from Outsiders to Insiders}

Just before 1800, but after the abandonment of the phlogiston theory, the term Earth came to mean an oxide that cannot be reduced at red heat either by hydrogen or carbon, the prototype of which was alumina. Initiated by the discovery of yttria (= YtterErde) isolated during the wet analysis of ytterbite ores (now known as gadolinite) by Gadolin in 1794, a series of five additional, but closely related earths were discovered, followed by ceria (1803), lanthanum (1839), didymium (1839), terbium (1843) and erbium (1843), the last four members being the result of the relentless efforts of a single chemist, Carl Gustav Mosander. ${ }^{[1]}$ Apart from the immediate observation that ceria/cerium could undergo oxidation to give an almost insoluble hydroxide, the only noticeable chemical differences between these Rare Earths at that time relied on (i) a gradual change in basicity, lanthanum being the most basic (i.e. giving the less insoluble hydroxide) and erbium the least basic and (ii) some specific weak colors for their hydroxides. The absence of a periodic trend was embarrassing for Mendeleyev, who, seeking a table with eight columns, originally placed lanthanum in col- 
a)

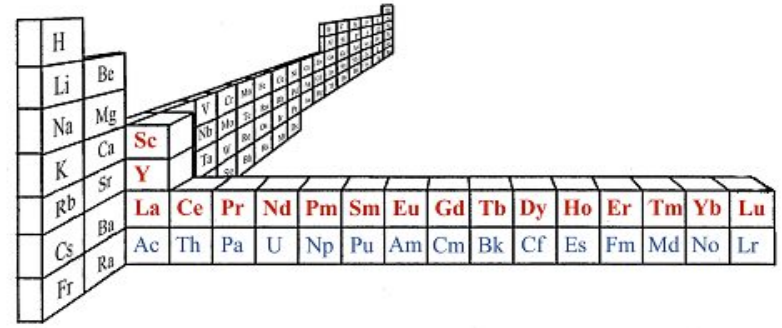

b)

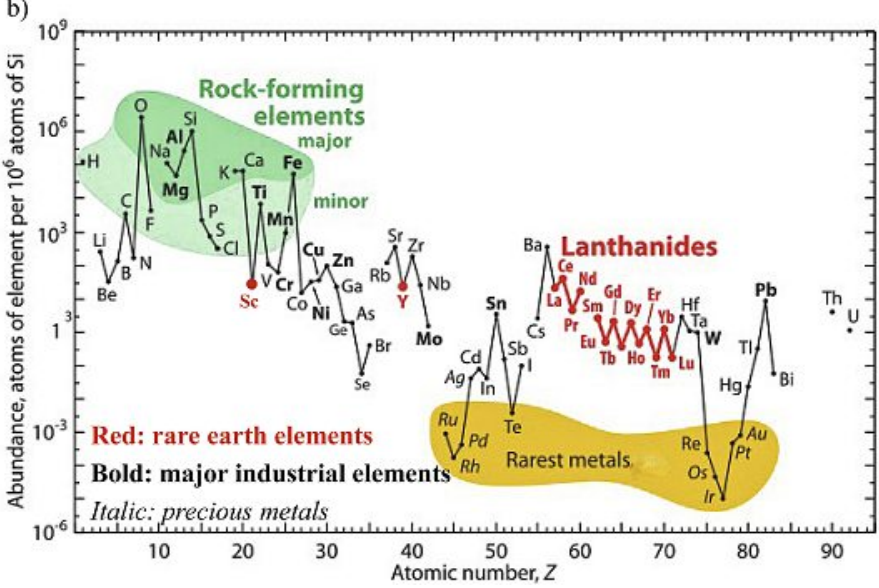

Fig. 1. a) Periodic table highlighting the location of Rare Earths (red elements). The elements shown in blue correspond to the actinide series.

b) Relative abundance of the Rare Earths in the earth crust (source: US Geological Survey).

umn III, cerium in column IV and didymium in column V in 1869, but could not find suitable locations for those other members of the series known at that time, or for those discovered after 1878. ${ }^{[5]}$ Crookes, after his lecture delivered at the Royal Institution in London in 1887 about the 'Genesis of the Elements', ${ }^{[6]}$ went on to suggest that a given element may have a variety of mass numbers (A values from the German term Atomgewicht) corresponding to almost the same chemical properties. He called these 'isotopes' meta-elements and suggested that the unclassifiable Rare Earths belonged to this class, which attenuated for a while the criticisms concerning the periodic table and the lack of regular places for these elements. This new way of thinking opened the door to the announcement of spurious new Rare Earths such as Incognitum and Victorium by Crookes himself, and Philippium and Decipium by Delafontaine. [7] Thanks to Marignac, who held the chair of inorganic chemistry at the University of Geneva during the second part of the $19^{\text {th }}$ century, Switzerland can take pride in the discovery and careful characterization of two new elements: ytterbium (1878) and gadolinium (1880). Around the beginning of the $20^{\text {th }}$ century, twelve of our lanthanides, i.e. the 15 elements following (and including) lanthanum (Fig. 1a), were well established, but it was not realized before 1913 and the recognition of the 'Aufbau principle' of the periodic table promoted by Bohr and Moseley, which was later judiciously formulated for polyelectronic atoms with the help of wave mechanics, that there were exactly three missing in 1900..$^{[8]}$ The assignment of the electronic structures of the gaseous lanthanides to [Xe] $6 \mathrm{~s}^{2} 4 \mathrm{f}^{n}$ (or [Xe] $6 \mathrm{~s}^{2} 4 \mathrm{f}^{n-1} 5 \mathrm{~d}^{1}$ for $\mathrm{Ln}$ $=\mathrm{Ce}, \mathrm{Gd}$ and $\mathrm{Lu}){ }^{[2]}$ characterized by the gradual filling of the valence $4 \mathrm{f}$ subshell, shed light on their similar chemical properties while their optical signatures were completely different. Indeed, a simple look at the weighted square of the radial functions $4 \pi r^{2} R_{n}^{2}$ of the hydrogenic wave functions (Fig. 2a) immediately shows that the $4 \mathrm{f}$ orbitals penetrate the xenon core while the filled $5 \mathrm{~s}^{2}$ and $5 \mathrm{p}^{6}$ subshells remain external, thus rendering the $4 \mathrm{f}^{n}$ valence electrons inaccessible for strong interactions with neighbouring atoms. ${ }^{[9]}$
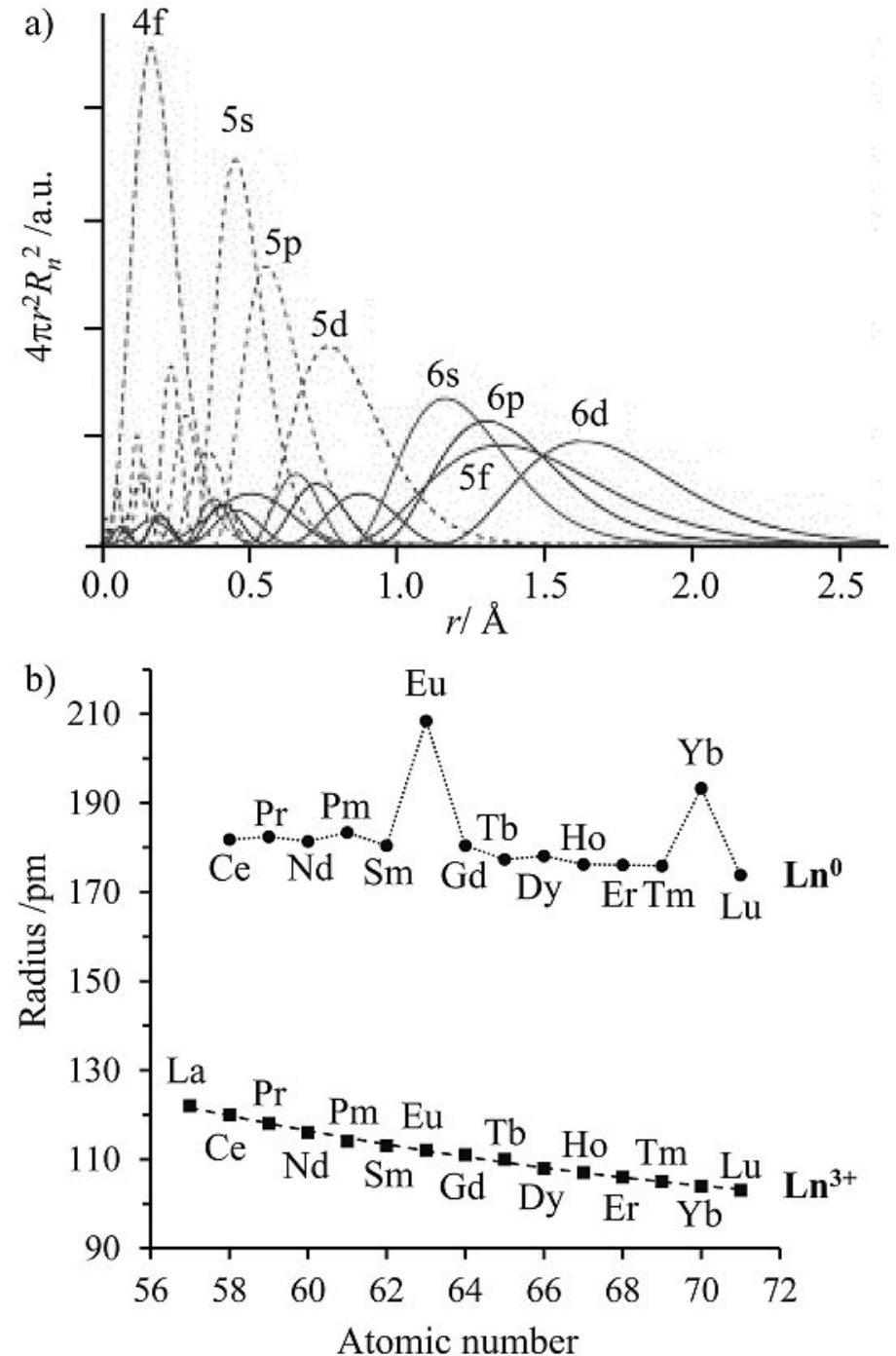

Fig. 2. a) Radial probabilities calculated for the hydrogenoid wavefunctions adapted for $\left.\mathrm{Ce}(0) .{ }^{[9]} \mathrm{b}\right)$ Atomic radii $\left(R_{\mathrm{Ln}(0)}^{\mathrm{CN}=12}\right)$ for twelve-coordinated $\mathrm{Ln}^{0}$ and ionic radi $\left(R_{\mathrm{Ln}(\mathrm{III})}^{\mathrm{CN}}\right)$ for nine-coordinated $\mathrm{Ln}^{3+}$ along the lanthanide series. ${ }^{[11]}$

In their usual trivalent state, $\mathrm{Ln}^{3+}$ ([Xe]4f $\mathrm{f}^{n}$ with $n=0$ for La to $n=14$ for $\mathrm{Ln}=\mathrm{Lu}$ ), the only noticeable differences in chemical reactivity arise from the expected contraction of the ionic radius along a period produced by incomplete screening effects according to Slater's rule (Fig. 2b). ${ }^{[10]}$ This trend is responsible for the stepwise increase in hydrolysis constants observed for the aquoions along the lanthanide series (i.e. $\left[\mathrm{La}\left(\mathrm{H}_{2} \mathrm{O}\right)_{n}\right]^{3+}$ is the least and $\left[\mathrm{Lu}\left(\mathrm{H}_{2} \mathrm{O}\right)_{n}\right]^{3+}$ is the most acidic aquo-ion of the series). Interest ingly, the metallic radii measured in solid-state samples (Fig. 2b) display similar global contraction except for the superimposition of two unexpected peaks for half-filled $\left(4 \mathrm{f}^{7}\right)$ and completely filled $\left(4 \mathrm{f}^{14}\right)$ electronic configurations. ${ }^{[11]}$ The mid-range effect, often referred to as the 'gadolinium break' effect since this element occupies the middle place in the lanthanide series, is highlighted even better when considering the third ionization energy transforming $\mathrm{Ln}^{2+}\left([\mathrm{Xe}] 4 \mathrm{f}^{n}\right)$ into $\mathrm{Ln}^{3+}\left([\mathrm{Xe}] 4 \mathrm{f}^{n-1}\right)$ with the release of one electron into the gas phase (Fig. 3a).

According to Johnson, ${ }^{[12]}$ the energy of the valence $4 \mathrm{f}^{n}$ subshell may be broken down into two major components. First, the coulombic attraction $(U)$ between the positively charged xenon core and each $f$ electron produces a global $-n U$ stabilization of the $4 \mathrm{f}^{n}$ configuration as shown in Eqn. (1). Secondly, the expected repulsion between the valence electrons is itself separated into two parts. The first part corresponds to the classical repulsive coulombic interaction mediated by the two-electron coulombic 
a)

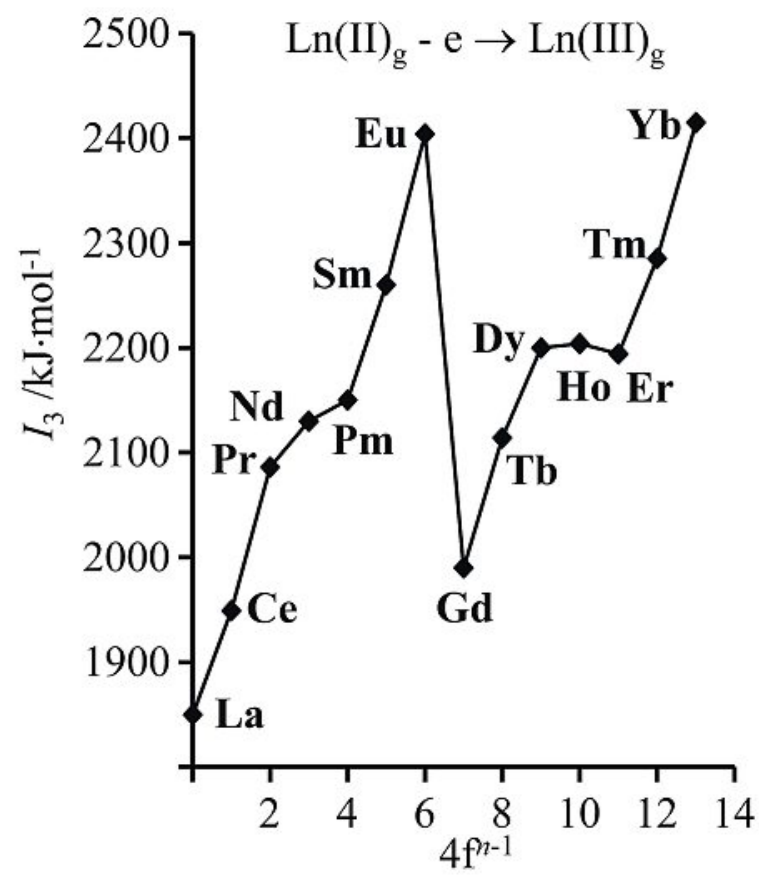

b)

\begin{tabular}{llll|llll}
\hline $\mathrm{Ln}^{2+}$ & $4 \mathrm{f}^{n}$ & $m$ & $\delta m$ & $\mathrm{Ln}^{3+}$ & $4 \mathrm{f}^{n}$ & $m$ & $\delta m$ \\
\hline $\mathrm{La}$ & $4 \mathrm{f}^{1}$ & 0 & 0 & $\mathrm{Gd}$ & $4 \mathrm{f}^{8}$ & 21 & 0 \\
$\mathrm{Ce}$ & $4 \mathrm{f}^{2}$ & 1 & 1 & $\mathrm{~Tb}$ & $4 \mathrm{f}^{9}$ & 22 & 1 \\
$\mathrm{Pr}$ & $4 \mathrm{f}^{3}$ & 3 & 2 & $\mathrm{Dy}$ & $4 \mathrm{f}^{10}$ & 24 & 2 \\
$\mathrm{Nd}$ & $4 \mathrm{f}^{4}$ & 6 & 3 & $\mathrm{Ho}$ & $4 \mathrm{f}^{11}$ & 27 & 3 \\
$\mathrm{Pm}$ & $4 \mathrm{f}^{5}$ & 10 & 4 & $\mathrm{Er}$ & $4 \mathrm{f}^{12}$ & 31 & 4 \\
$\mathrm{Sm}$ & $4 \mathrm{f}^{6}$ & 15 & 5 & $\mathrm{Tm}$ & $4 \mathrm{f}^{13}$ & 36 & 5 \\
$\mathrm{Eu}$ & $4 \mathrm{f}^{7}$ & 21 & 6 & $\mathrm{Yb}$ & $4 \mathrm{f}^{14}$ & 42 & 6 \\
\hline
\end{tabular}

Fig. 3. a) Third ionization energies along the lanthanide series and $b$ ) number of electron pairs with parallel spins $m\left(f^{n}\right)$ for the $\mathrm{Ln}^{2+}$ cations and computed $\delta m=m\left(f^{n}\right)-m\left(f^{n-1}\right)$ coefficients required in Eqn. (2). ${ }^{[12]}$

integrals $J$, which contribute by $\left({ }^{n} C_{2}\right) J$ to the global energy of the valence subshell where ${ }^{n} C_{2}=n ! /(n-2) ! 2$ ! is the number of possible pairs of electrons in the $4 \mathrm{f}^{n}$ configuration (Eqn. (1)). The second part has no classical counterpart and results from the stabilizing two-electron exchange energies $K$ at the origin of Hund's rule. A reasonable assumption considers a roughly proportional relationship between an average pair exchange energies $K$ and the number of possible pairs of parallel spins $m$, thus completing Eqn. (1) with an ultimate stabilization of $-m K$.

$$
E\left(\mathrm{f}^{n}\right)=-n U+{ }^{n} C_{2} J-m K
$$

With this tool in hand, the third ionization potential is given simply by Eqn. (2) and the pertinent coefficients $\delta m=m\left(\mathrm{f}^{n}\right)-$ $m\left(\mathrm{f}^{n-1}\right)$ are collected in Fig. $3 \mathrm{~b}$.

$$
\begin{aligned}
I_{3} & =E\left(\operatorname{Ln}^{3+}\right)-E\left(\operatorname{Ln}^{2+}\right)=E\left(\mathrm{f}^{n-1}\right)-E\left(\mathrm{f}^{n}\right) \\
& =U-(n-1) J+\left(m\left(\mathrm{f}^{n}\right)-m\left(\mathrm{f}^{n-1}\right)\right) K
\end{aligned}
$$

The regular increase of the positive values of the nuclear potential $U$ felt by the 4 f electrons along the lanthanide series is more or less balanced by the parallel regular increase of the coulombic electron-electron repulsion measured by $-(n-1) J$. Therefore no special break along the series arises from the two first terms in Eqn. (2). Any significant break thus finds its origin in the irregular variation of the exchange energies $\delta m K=\left[m\left(\mathrm{f}^{n}\right)-m\left(\mathrm{f}^{n-1}\right)\right] K$. Fig. 3 bredicts that (i) $\delta m$ is positive or zero and (ii) $\delta m$ shows abrupt changes for half-filled and filled $4 \mathrm{f}$ orbitals, which explains the unexpected variation of some electronic properties around $4 \mathrm{f}^{7}$ and $4 \mathrm{f}^{14}$ as highlighted for the third ionization potential (Fig. 3a) and for the metallic radii (Fig. 2b). The additional minor effects at $1 / 4$ (around $\mathrm{Nd}$ ) and 3/4 (around Ho, see Fig. 3a) in the series are due to some minor variations of $K$ along the lanthanide series arising from weaker inter-spin correlations when the sign of the magnetic quantum number changes. ${ }^{[12]}$ The above rationalization focused the search for the divalent state on $\mathrm{Sm}, \mathrm{Eu}, \mathrm{Tm}$ and $\mathrm{Yb}$, where the third ionization potential is greatest (see Fig. 3a). ${ }^{[13]}$ The chemical properties along the series are often very similar, but the physical properties (magnetism and optics), which rely on the specific location of the different electrons within the $4 \mathrm{f}^{n}$ subshell may be very different. Furthermore, because of the lack of perturbation of the valence electrons by neighboring atoms, the specific electronic properties of the free ions are maintained in the various compounds. The simple Russell-Saunders coupling scheme thus provides satisfying and predictable energy levels for the ground and the excited ${ }^{2 S+1} L_{J}$ spectroscopic levels along the lanthanide series (Fig. 4). ${ }^{[14]}$ Further ultrafine energy splitting arises from the even part of the crystal-field Hamiltonian, ${ }^{[15]}$ while the intensity of the radiative transitions between these levels can be estimated by the odd part of the same crystal-field Hamiltonian. ${ }^{[16]}$

Just after the second World war, the story of the Rare Earths ended with the isolation of the last 'natural' element of the periodic table, promethium $(Z=61)$, previously detected by its spectroscopic signature in enriched wastes collected during the Manhattan project. The instability of its nuclear core, predicted by the nucleon shell model of Maria Goeppert-Mayer, explains (or at least justifies) the short half-life and the almost impossible detection of promethium in natural ores. ${ }^{[17]}$ Despite the original reluctance of Mendeleyev to consider Rare Earths as valid partners in 1869, fifteen lanthanide elements ( $\mathrm{La}-\mathrm{Lu}$ ) with very similar chemical properties finally found their place in the periodic table. Except for some niche, but profitable applications during the first half of the $20^{\text {th }}$ century as incandescent mantles, flints for lighters and additives in metallurgy, for which no precise and reliable separation was required, Rare Earth chemistry, and particular molecular chemistry, was essentially ignored during this period. ${ }^{[18,19]}$

\section{Some Breakthroughs Brought by Rare Earths in Chemistry.}

At the time of publication of Mendeleev's periodic table in $1869,89 \%$ of the natural transition elements had already been discovered ( 24 d-block elements among 27 collected in columns 4-12 as shown in Fig. 5), while only 35\% of the Rare Earths were identified. This situation is symptomatic of a classical trend in transition metal chemistry throughout history: Rare Earth chemistry has (almost) systematically followed d-block chemistry. The reluctance of Rare Earths to adopt oxidation states other than trivalent forced chemists at the turn of the $19^{\text {th }}$ century to exploit extensively $\mathrm{pH}$-controlled fractional crystallization of complicated aqueous double nitrate or sulfate salts for their separation. ${ }^{[20]}$ These repetitive manipulations did not help Alfred Werner to contradict the maximum coordination number of four firmly established for p-block centres by Abegg and Lewis. ${ }^{[21]}$ The exceptional stabilities and kinetic inertness of the coordination complexes formed between trivalent d-block cations, especially $\mathrm{Co}(\mathrm{III})$, and linear polyamine ligands, which are at the origin of a satisfying description of the molecular structures of transition metals displaying preferred coordination numbers between 4 and 6 , had no 


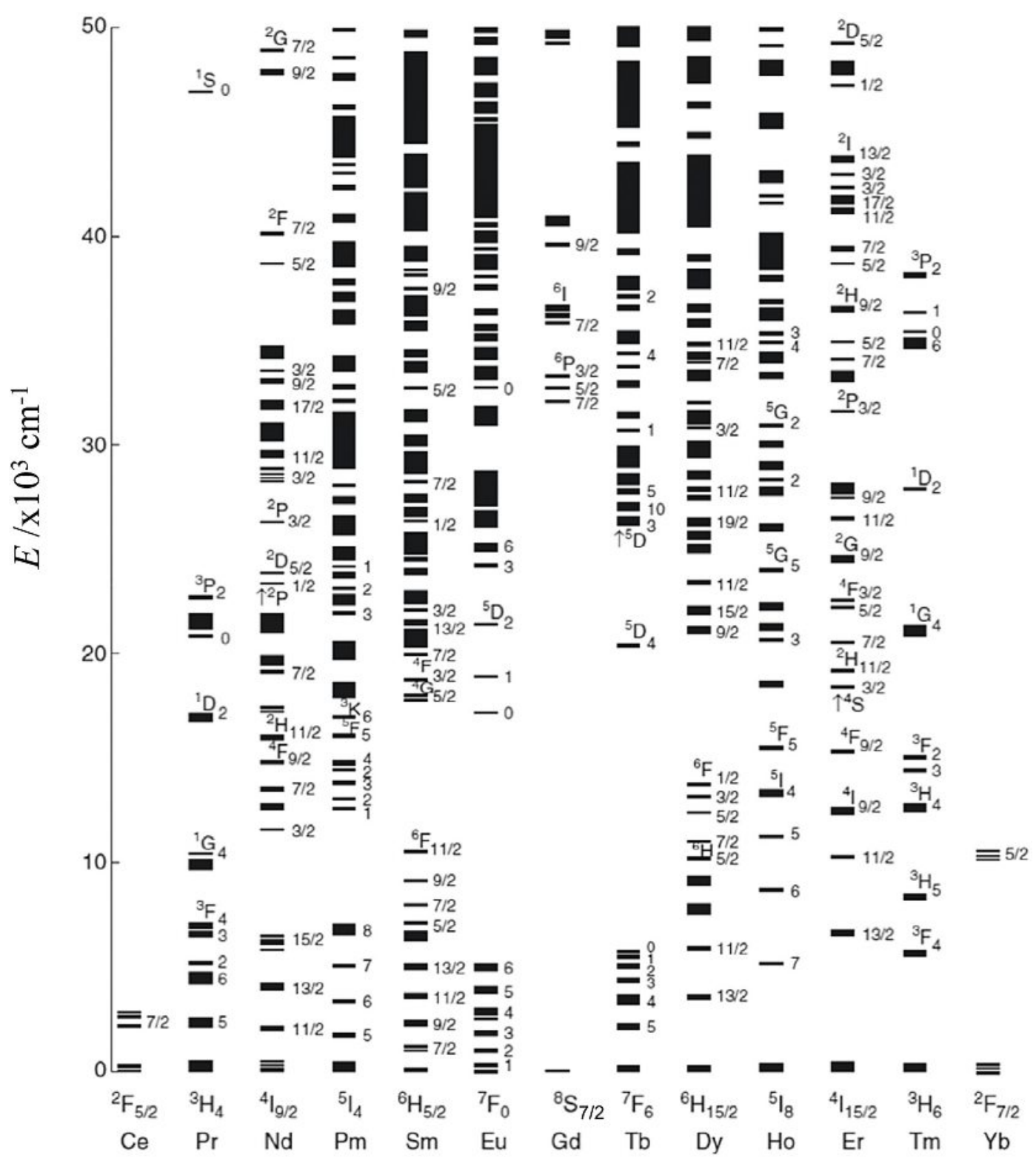

Fig. 4. Dieke diagram showing the spectroscopic levels of trivalent lanthanide free ions. ${ }^{[14]}$ counterpart for $4 \mathrm{f}$-block cations since the latter did not allow the isolation of geometrical isomers to help elucidate their structures. The pioneer work of Urbain, who used neutral [ $\left.\mathrm{Ln}(\mathrm{acac})_{3}\right]$ complexes in extraction procedures, was taken as a strong support for six-coordination along the lanthanide series, as found for d-block complexes, because acetylacetonate (acac-) was known to act as a bidentate chelating anion, ${ }^{[22]}$ and this despite two pioneer X-ray crystal structures reporting nine-coordinate metallic centers in the solvated salts $\mathrm{Ln}\left(\mathrm{C}_{2} \mathrm{H}_{5} \mathrm{OSO}_{3}\right)_{3} \cdot 9 \mathrm{H}_{2} \mathrm{O}$ and $\mathrm{Nd}\left(\mathrm{BrO}_{3}\right)_{3} \cdot 9 \mathrm{H}_{2} \mathrm{O}$. ${ }^{[23]}$

The intense activity centered in Zurich during the late fifties and focused on the efficient sequestration of various cations by using multidentate chelate ligands such as 2,2',2"-nitrilotriacetic acid (NTA), 2,2',2",2"'-(ethane-1,2-diyldinitrilo)tetraacetic acid (EDTA) or diethylenetriaminopentaacetic acid (DPTA) ${ }^{[24]}$ reactivated the investigation of coordination numbers around trivalent lanthanides, which were finally established as greater than 6 by the crystal structures solved for $\mathrm{NH}_{4} \mathrm{La}(\mathrm{EDTA}) \cdot 8 \mathrm{H}_{2} \mathrm{O}(\mathrm{CN}=10)^{[25]}$ and $\left.\mathrm{HLa}(\mathrm{EDTA}) \cdot 7 \mathrm{H}_{2} \mathrm{O}(\mathrm{CN}=9) .{ }^{4} 6\right]$ Because of the inner-shell character of the $4 \mathrm{f}$ valence electrons, the lanthanide cations show negligible ligand-field effects and consequently no stereochemical preference. Combined with their large and variable coordination numbers, trivalent lanthanides are often considered as the chameleons of coordination chemistry and were therefore not considered as templating agents or, more simply, as reliable metal centers for organizing peripheral ligands in both solution-phase and solid-state chemistry. ${ }^{[27]}$ The situation changed slightly with the improved structural programming brought by cooperative multiple interactions implemented in metallosupramolecular chemistry. For instance, the mixing of the segmental di-didentate ligand L1 with a six-coordinate d-block divalent cobalt cation led to what was believed to be a highly sophisticated triple-helical structure in 1991 (Fig. 6a), ${ }^{[28]}$ but which appears twenty-five years later rather old-fashioned when one considers the quadruple-stranded helices obtained by the reaction of a similar di-didentate receptor $\mathbf{L} \mathbf{2}$ with trivalent 4f-block dysprosium (Fig. 6b). ${ }^{\text {[29] }}$

A similar downgrading of the summit of complexity is found in the template synthesis of the trefoil molecular knot $\left[\mathrm{Cu}_{2} \mathbf{L} \mathbf{3}\right]^{2+}$, which originally used a complicated double-stranded dinuclear d-block precursor and contributed to the award of the Nobel prize in chemistry to Sauvage in 2016 (Fig. 7a). ${ }^{[30]}$ Moving to larger coordination numbers around $4 \mathrm{f}$-block trivalent europium cations provides the same result using a 'simple' mononuclear template (Fig. 7b).[31]

Apart from their larger coordination numbers, 4f-block cations show the maximum number of unpaired electrons in the periodic table (seven for $\mathrm{Gd}^{3+}$ ). Combined with the operation of non-negligible spin-orbit coupling effects for heavy elements, the electron-electron repulsion within the $4 \mathrm{f}$ subshell yields between one (for $\mathrm{Ce}\left(4 \mathrm{f}^{1}\right)$ and $\mathrm{Yb}\left(4 \mathrm{f}^{13}\right)$ ), and 325 (for $\operatorname{Gd}\left(4 \mathrm{f}^{7}\right)$ ) excited spectroscopic levels, some of which are emissive (Fig. 4). With such a supply of excited 


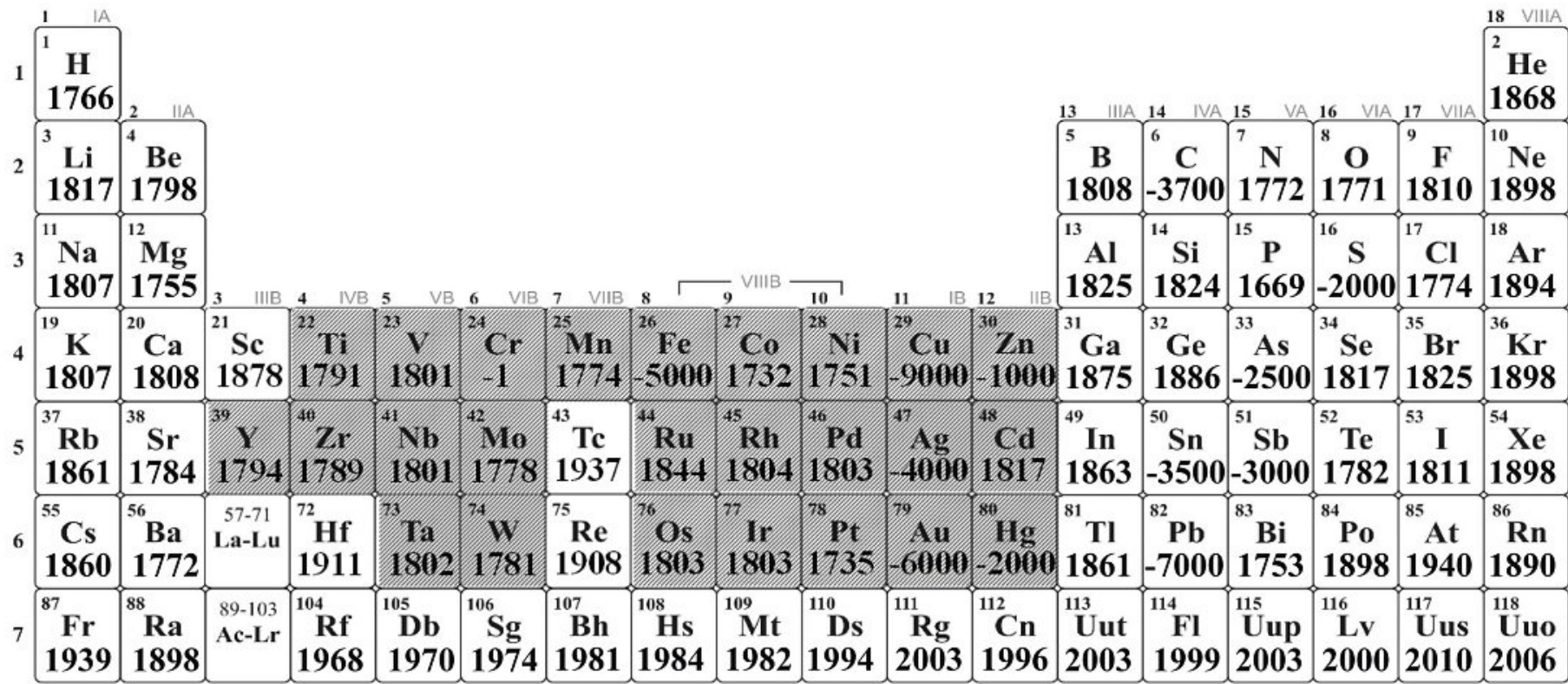

\begin{tabular}{|c|c|c|c|c|c|c|c|c|c|c|c|c|c|c|}
\hline 1.2 & 180 & $\begin{array}{l}{ }^{59} \\
1885\end{array}$ & $\begin{array}{l}18 \mathrm{~d} \\
18 \mathrm{~s}\end{array}$ & $\begin{array}{l}{ }^{1} \\
\text { Pm } \\
1947\end{array}$ & $\begin{array}{c}\text { 62 } \\
\text { Sm } \\
1879\end{array}$ & $\begin{array}{c}{ }^{63} \mathbf{E u} \\
\mathbf{E u} \\
1901\end{array}$ & $\mid \begin{array}{c}64 \\
\mathbf{G d} \\
\mathbf{1 8 8 0}\end{array}$ & 18 & $\begin{array}{l}{ }^{666} \text { Dy } \\
1886\end{array}$ & $\begin{array}{c}\text { Ho } \\
\mathbf{H o} \\
1879\end{array}$ & $18+2$ & $\begin{array}{r}{ }^{69} \\
\text { Tm } \\
1879\end{array}$ & $\begin{array}{c}{ }^{70} \mathrm{Yb} \\
1878\end{array}$ & $\begin{array}{c}71 \\
\mathbf{L u} \\
1907\end{array}$ \\
\hline $\begin{array}{c}\text { Ac } \\
1899\end{array}$ & 1829 & 1913 & & $\begin{array}{c}\text { Np } \\
1940\end{array}$ & $\begin{array}{l}{ }^{94} \mathrm{Pu} \\
1941\end{array}$ & & $\begin{array}{r}\mathrm{Cm} \\
1944\end{array}$ & $\begin{array}{c}\text { BK } \\
1949\end{array}$ & $\begin{array}{c}\mathbf{C f} \\
1950\end{array}$ & $\begin{array}{c}\text { Es } \\
1952\end{array}$ & Fm & $\begin{array}{c}\text { Md } \\
1955\end{array}$ & $\begin{array}{l}{ }_{102}^{N 0} \\
1958\end{array}$ & 1961 \\
\hline
\end{tabular}

Fig. 5. A periodic table showing the date of the discovery of each element. The greyish part highlights the 24 transition metals (d-block) and the 6 lanthanides (4f-block) elements already isolated in 1869. The dydimium of Mosander, discovered in 1839, indeed corresponded to a mixture of praseody(di)mium and neody(di)mium separated in 1885 by Auer von Welsbach. ${ }^{[1]}$
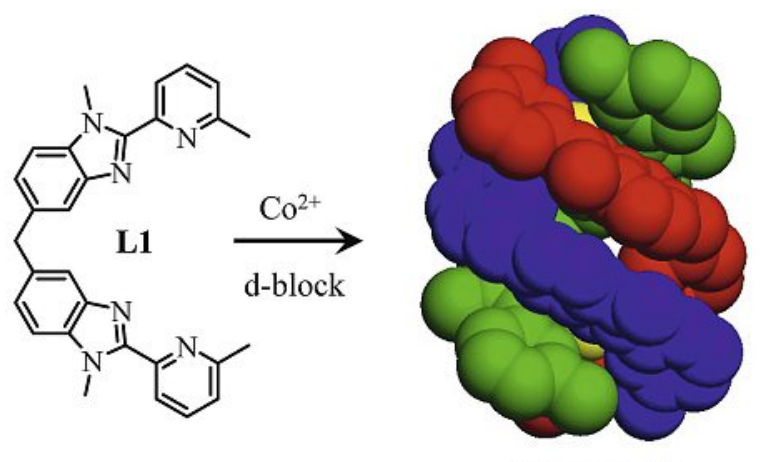

$\left[\mathrm{Co}_{2}(\mathbf{L 1})_{2}\right]^{4+}$
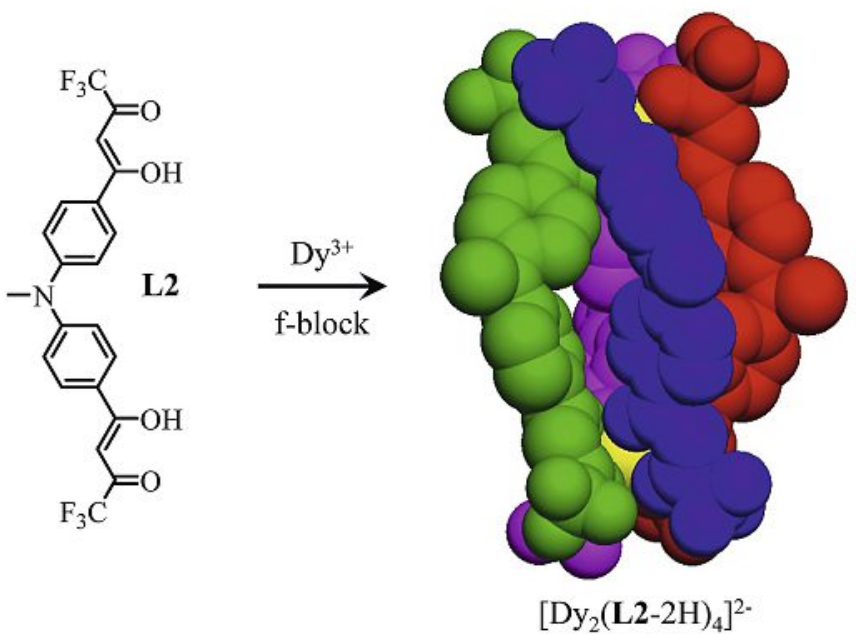

Fig. 6. Self-assembly of a) triple-stranded ${ }^{[28]}$ and b) quadruple-stranded ${ }^{[29]}$ dinuclear helicates using di-didentate segmental ligands. The X-ray crystal structures of charged complexes are shown with different colors for each strand. Hydrogen atoms have been omitted for clarity. a)
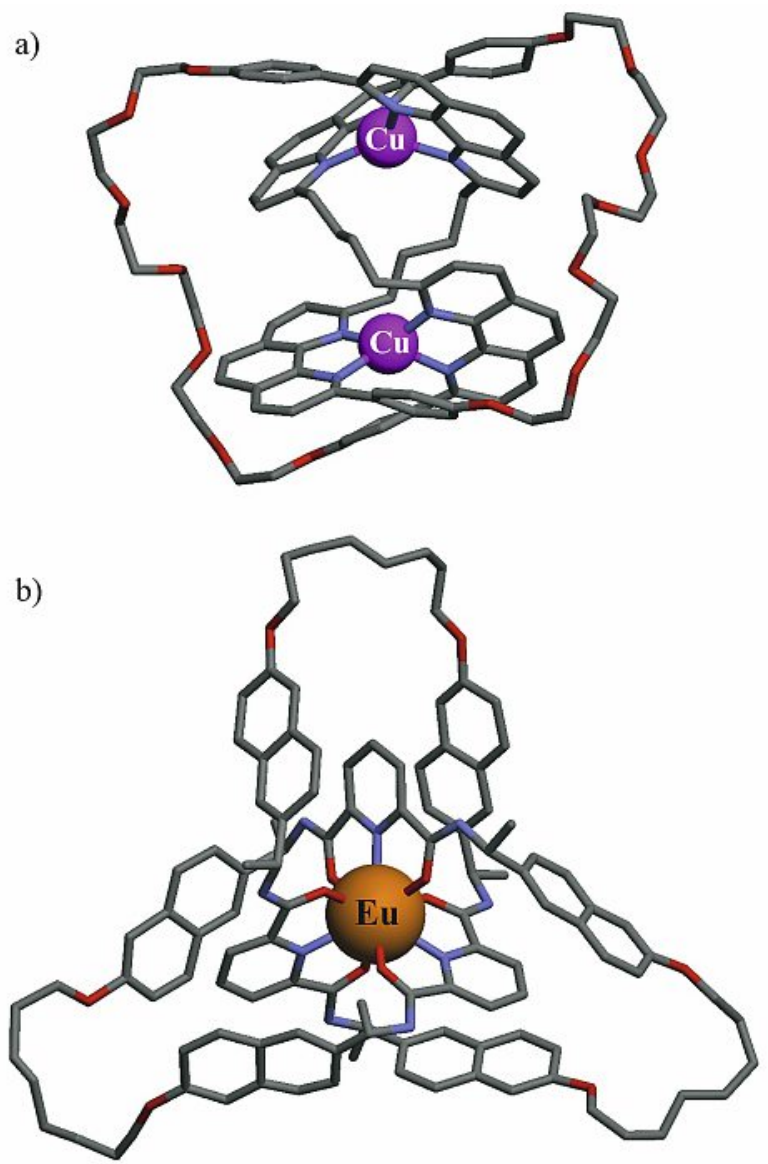

Fig. 7. Molecular structures of trefoil knots obtained by metal-templated reactions using a) d-block ${ }^{[30]}$ and b) f-block ${ }^{[31]}$ cations. Hydrogen atoms have been omitted for clarity. Color code: $\mathrm{C}=$ grey, $\mathrm{N}=$ blue, $\mathrm{O}=$ red. 
states displaying long radiative lifetimes due to the parity-forbidden nature of the intrashell electric-dipole radiative transitions, it is rather surprising that the first coherent optical MASER beam (nowadays better known as a LASER beam for Light Amplification by Stimulated Emission of Radiation) was designed with $\mathrm{Cr}$ (III), a dblock cation doped into $\mathrm{Al}_{2} \mathrm{O}_{3},{ }^{[32]}$ and not with f-block cations since Ln(III)-based solid state lasers are currently far more common. [33]

Once intense and coherent excitations beamlines were available in 1960, physicists explored non-linear optical responses predicted theoretically by Goeppert-Mayer three decades before. [34] The first demonstration of second-harmonic generation (secondorder polarization $\sigma_{2}$ ) required only virtual excited states reached under intense irradiation of non-centrosymmetric quartz crystals with a ruby laser at $694 \mathrm{~nm}$ (Fig. 8a). ${ }^{[35]}$ On the other hand, the non-linear two-photon excitation leading to upconversion (thirdorder polarization $\sigma_{3}$ ) of a near-infrared excitation beam (694 $\mathrm{nm})$ into a visible blue emission $(425 \mathrm{~nm})$ exploited real excited states provided by $\mathrm{Eu}^{2+}$ cations doped into inorganic materials (Fig. 8b). ${ }^{[36]}$ However, due to the faint non-linear response of matter in general, Auzel advocated an alternative approach in which the low-energy photons are piled up using successive standard linear optical absorption processes (first-order polarization $\varepsilon$ ), ${ }^{[37]}$ a mechanism denoted 'excited state absorption (ESA)', which is several orders of magnitude more efficient than its non-linear two-photon excitation counterpart (Fig. 8c). ${ }^{[38]}$ Thanks to the exceptional choice of tunable and predictable metal-centered ${ }^{2 S+1} L_{J}$ spectroscopic levels found along the $4 \mathrm{f}^{n}$ series (Fig. 4), linear upconversion using either the ESA mechanism or an improved version of it, which involves energy transfer processes for the successive feeding of the Ln-centered excited levels (ETU for Energy

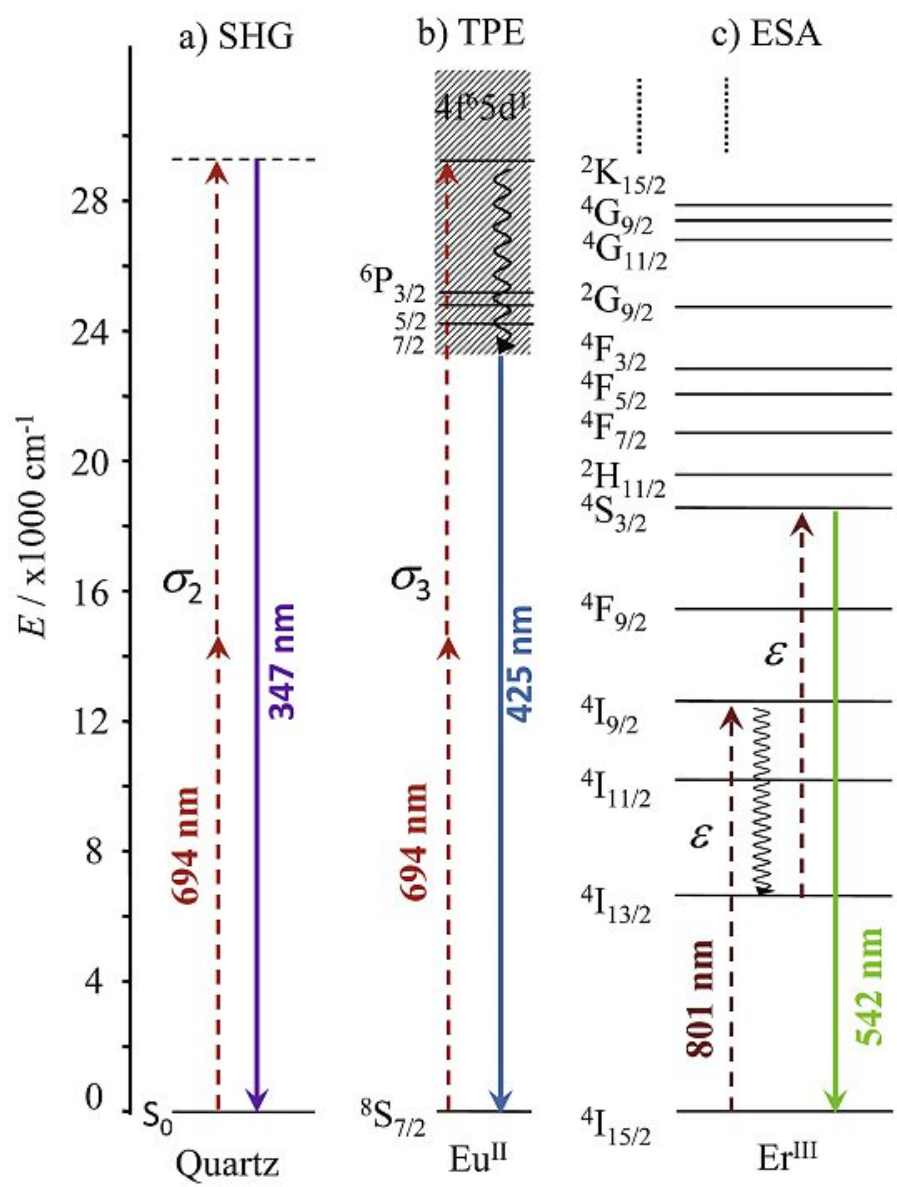

Fig. 8. Energy-level diagrams illustrating a) non-linear (second-order $\sigma_{2}$ ) second harmonic generation, ${ }^{[35]} \mathrm{b}$ ) non-linear (third-order $\sigma_{3}$ ) two-photon excitation $^{[36]}$ and c) linear (first-order $\varepsilon$ ) excited state absorption ${ }^{[37]}$ eventually leading to upconverted light emissions.
Transfer Upconversion) has found applications in the design of nanoparticles able to transform infrared light into visible light for probing biological materials ${ }^{[39]}$ and for harvesting additional irradiance in solar cells. ${ }^{[40]}$

a)
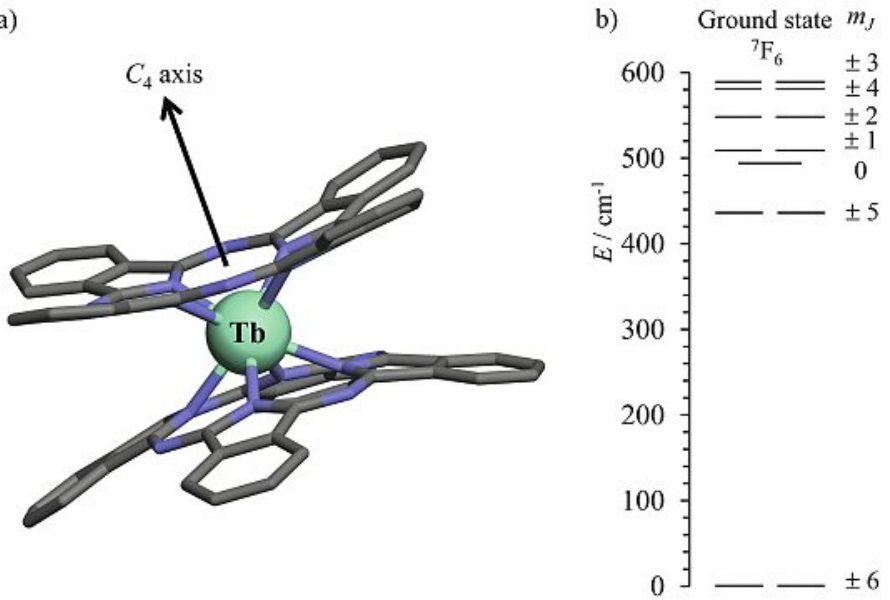

Fig. 9. a) Molecular structure and b) energy and $m$, values of the sublevels of the ground state multiplet ${ }^{7} \mathrm{~F}_{6}$ in the double-decker $\left[\mathrm{Tb}(\mathrm{Pc})_{2}\right]^{-}$ complex. ${ }^{[44]}$ Color code: $\mathrm{C}=$ grey, $\mathrm{N}=$ blue. Hydrogen atoms have been omitted for clarity.

Finally, as a result of the very weak crystal-field effects on the core $4 \mathrm{f}$-orbitals, their near degeneracy leads to large unquenched orbital momenta $L$, which has no counterpart in the d-block series. Moreover, the large spin-orbit coupling constants characterizing the second part of the periodic table mix $L$ with spin quantum number $S$ to give a total angular quantum number $J$ at the origin of (i) the largest magnetic moments for $\mathrm{Tb}(\mathrm{III})$ and $\mathrm{Ho}(\mathrm{III})^{[41]}$ and (ii) the largest magnetic anisotropies in the periodic table. ${ }^{[42]}$ These facts are well known to scientists who have long employed lanthanide elements for the design of materials with extraordinary magnetic properties, including the strongest magnets known $\mathrm{SmCo}_{5}$ and $\mathrm{Nd}_{2} \mathrm{Fe}_{14} \mathrm{~B}$. When limited to microscopic objects, the rational use of magnetic anisotropy to create switchable molecular-scale devices that store or manipulate information using the orientation of the molecular magnetic moment, i.e. single-molecule magnets (SMM), remained an unsolved problem so long as the only source of anisotropy was the elusive and small zero-field splitting coupled with a high-spin ground state arising from ferromagnetic interactions in multinuclear d-block molecules such as $\left[\mathrm{Mn}_{12} \mathrm{O}_{12}\left(\mathrm{O}_{2} \mathrm{CCH}_{3}\right)_{16}\left(\mathrm{H}_{2} \mathrm{O}\right)_{4}\right] \cdot{ }^{[43]} \mathrm{In}$ 2003, Ishikawa and coworkers realized that the small crystal-field effects responsible for the splitting of the $J$ quantum number of trivalent lanthanides in complexes to give $2 J+1$ projections along the $z$ quantification axis ( $m_{J}$ values) result in an energetic barrier for the inversion of the total magnetic moment, which can be more than $1000 \%$ higher than those obtained previously by zero-field splitting. ${ }^{[44]}$ Plots of the AC magnetic susceptibilities measured for a series of ${ }^{n} \mathrm{Bu}_{4} \mathrm{~N}\left[\mathrm{Ln}(\mathrm{Pc})_{2}\right]$ double-decker complexes with $\mathrm{Ln}=\mathrm{Tb}(\mathrm{III})$ or Dy(III) in axial $\left(C_{4}\right)$ environments ( $\mathrm{Pc}=$ phthalocyanine dianion, Fig. 9a) show slow magnetization relaxation behavior with an energetic barrier of $230 \mathrm{~cm}^{-1}$ for $\mathrm{Ln}=\mathrm{Tb}$ (modeled with the help of a simple Arrhenius law), a value about one order of magnitude larger than that found for $\left[\mathrm{Mn}_{12} \mathrm{O}_{12}\left(\mathrm{O}_{2} \mathrm{CCH}_{3}\right)_{16}\left(\mathrm{H}_{2} \mathrm{O}\right)_{4}\right]^{[}{ }^{[42]}$ This barrier height roughly matches the largest energy gap calculated between two successive $m_{J}$ states $\left(400 \mathrm{~cm}^{-1}\right.$, Fig. $\left.9 \mathrm{~b}\right)$, which led Ishikawa to conclude that the magnetic relaxation of these single-ion magnets (SIM) occurs through a path consisting of stepwise transitions from $m_{J}$ to $m_{J} \pm 1$ states, the 'rate-determining step' being the first transition from $m_{J}=6$ to $m_{J}=5$ (or -6 to -5 ) in ${ }^{n} \mathrm{Bu}{ }_{4} \mathrm{~N}\left[\mathrm{~Tb}(\mathrm{Pc})_{2}\right]$ (Fig. 9b). Subsequent optimization of the crystal-field effects using low-coordination numbers together with pentagonal symmetries 
nowadays extend energetic barriers beyond $1000 \mathrm{~cm}^{-1}$ for Kramer's Dy(III) cations, which correspond to maximum blocking temperatures around $60 \mathrm{~K} .{ }^{[45]}$

\section{Rare Earths as Building Blocks in a Technically Oriented Society}

As illustrated in Fig. 1b, Rare Earths are not particularly rare in the earth's crust and their specific charge over size ratios (electrostatic factors $z^{2} / R$ ) combined with the particular optical and magnetic properties arising from their unprecedented inner openshell $4 \mathrm{f}^{n}$ electronic configurations made them vital components for a wealth of advanced materials and modern technologies, such as catalysts for organic chemistry (moisture-insensitive Lewis acids, gas oil cracking and exhaust gas depollution), intense magnets, optics and lasers, economic lighting, wind- and solar-energy conversion, rechargeable hybrid batteries, conducting ceramics, magnetic and optical probes in medicine and components in electronics and in metallurgy (Fig. 10a). ${ }^{[18]}$

For the general public, Rare Earths are mainly known for their use in miniaturized magnets for cell phones $\left(\mathrm{SmCo}_{5}\right.$ and $\mathrm{Nd}_{2} \mathrm{Fe}_{14} \mathrm{~B}$ ), as catalysts for transforming $\mathrm{CO}$ into $\mathrm{CO}_{2}$ in internal combustion engines $\left(\mathrm{CeO}_{2-x}\right)$, as contrast agents for improving the quality of magnetic resonance imaging for medical diagnosis (Gd-DOTA) and as phosphors for flat displays ( $\mathrm{red}=\mathrm{Eu}^{3+}$, green $=\mathrm{Tb}^{3+}$, blue $=\mathrm{Eu}^{2+}$ or $\mathrm{Tm}^{3+}$ ). The use of Rare Earths in many objects with high-economic potential (cars, cell phones, electronic displays, light-emitting diodes, optical fibres, medical scanners) and in restricted military applications (guidance systems, nightvision binoculars), makes them highly sensitive to economic and political instabilities. Although global deposits of Rare Earths are spread over the five continents (Fig. 10b), ${ }^{[46]}$ most of the facilities to mine and separate Rare Earths are based in China, which decided to limit exports of these materials in 2009 and 2010. In a
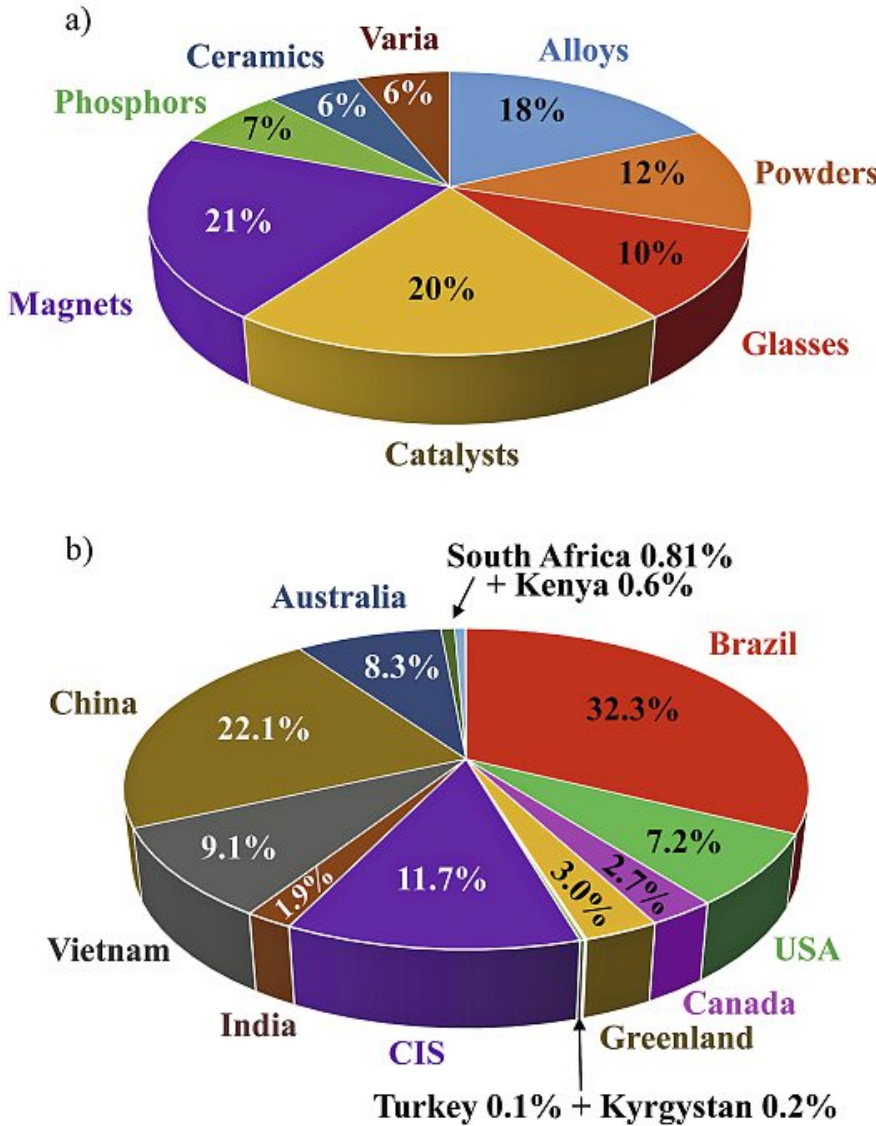

Fig. 10. a) Weight percentages of Rare Earths used in their principal applications in 2009 (data taken from the US Geological Survey ${ }^{[18]}$ and b) global Rare Earths deposits in 2010. ${ }^{[46]}$ subsequent alarming report, the U.S. Department of Energy envisioned a possible 'critical shortage' of five Rare Earth elements, especially dysprosium - crucial to the permanent magnets used in wind turbines and motors in hybrid or electric cars - and the prices of the Rare Earths increased suddenly by roughly an order of magnitude. As often in economics, the induced perturbation had no really rational origin and the absence of significant increasing world demand for Rare Earths restored normal prices few years later (Fig. 11). ${ }^{[47]}$

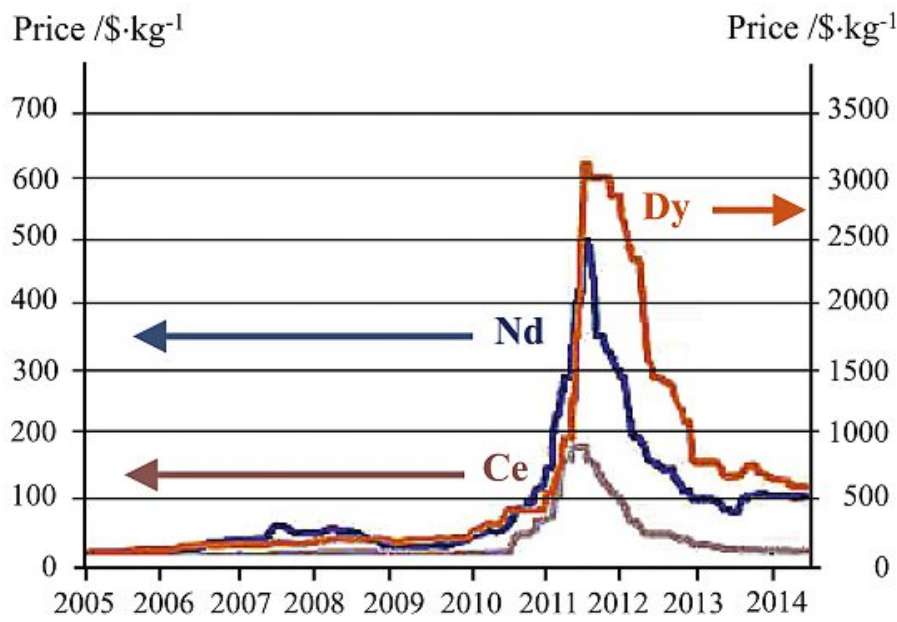

Fig. 11. Rare Earth prices before, during and after the Rare Earth 'crisis' (data from Thomson-Reuters Datastream). ${ }^{[4]}$

Apart from the well-established profitable industrial applications summarized briefly in Fig. 10a, the exceptional optical and magnetic properties of Rare Earths have encouraged their introduction into various innovative materials such as liquid crystals (lanthanidomesogens), ${ }^{[48]}$ hybrid materials, ${ }^{[49]}$ nanoparticles ${ }^{[50]}$ and metallopolymers (lanthanidopolymers) ${ }^{[51]}$ for implementing novel electronic properties which are inaccessible with other elements. This specificity is not limited to material sciences, but synthetic organic chemists have also benefited from the Lewis acid character of trivalent cations (Shibasaki's catalysts) and of the strong redox agents provided by $\mathrm{SmI}_{2}$ (Kagan's reagent, strongly reducing) or by $\left[\mathrm{Ce}\left(\mathrm{NO}_{3}\right)_{6}\right]^{2-}$ (Ceric ammonium nitrate, $\mathrm{CAN}$, strongly oxidizing). ${ }^{[52]}$ Finally, high-resolution bioimaging, which has an important potential for image-guided in vivo surgery, is currently limited by the autofluorescence of tissues and by the short penetration of visible light into biological materials. ${ }^{[53]}$ The first issue can be addressed by using long-lived lanthanide bioprobes coupled to timeresolved detection, while the second limitation can be overcome by the use of NIR-NIR bioprobes, in which $\mathrm{Yb}(\mathrm{III})$ is responsible for NIR light harvesting $(980 \mathrm{~nm})$ and $\mathrm{Er}(\mathrm{III})$ for light emission (1525 $\mathrm{nm})$. Combining these two aspects in multilayered downshifting nanoparticles recently led to the achievement of time-domain multiplexing of three different receptors in cancer tumors. ${ }^{[54]}$

\section{Conclusion}

Because of their open inner-shell character, the $4 \mathrm{f}^{n}$ electronic configurations specific to each trivalent lanthanide do not result in any major differences in chemical reactivity, which makes these elements of limited interest when building a table based on periodic properties. The stepwise and smooth contraction of their ionic radii with increasing atomic number is often sufficient to rationalize both thermodynamic and kinetic properties along the series, whereas minor discontinuities, such as uneven changes in ionization energies or in $\mathrm{Ln}^{3+} / \mathrm{Ln}^{2+}$ redox potentials reflect intimate intra-shell electron-electron interactions. Related effects in the dblock series are usually dominated or masked by chemical bonding. 
Once it was realized that atomic quantum physics applies to $4 \mathrm{f}^{n}$ lanthanides in molecular compounds with only very few distortions brought by peripheral electric fields (i.e. crystal-field), the rational programming and tuning of both magnetic (ground state) and optical (excited states) properties justify the enthusiasm for their use as building blocks for modern technologies and applications. Given the lack of stereochemical preferences along the lanthanide series, coordination chemistry and metallosupramolecular chemistry essentially use lanthanides as empirically adjustable centers, but their large coordination number is clearly underexploited for creating complexity in molecular-based objects. When incorporated into nanoparticles, hydrid materials or ionic solids, the search for precise structural programming becomes secondary but their fascinating electronic properties are worth optimization, and this at whatever level of molecular description. Freed from academic reticence, the future of lanthanides-containing materials will be bright in our economically-driven society at the beginning of this 21 st century.

\section{Acknowledgements}

Financial support from the Swiss National Science Foundation is gratefully acknowledged.

Received: January 16, 2019

[1] a) F. Szabadvary, in 'Handbook on the Physics and Chemistry of Rare Earths', Eds. K. A. Gschneidner Jr, L. Eyring, Elsevier, 1988, 11, pp 33-80; b) L. Ninistö, in 'Rare Earths', Eds. R. Saez, P.A. Caro, Editorial Complutense, Madrid, 1998, pp 25-42.

[2] a) S. Cotton, 'Lanthanide and Actinide Chemistry', John Wiley \& Sons, Ltd, Chichester, 2006; b) J.-C. G. Bünzli, in 'Kirk-Othmer Encyclopedia of Chemical Technology', John Wiley \& Sons, 2013, pp 1-43.

[3] a) J. Kido, Y. Okamoto, Chem. Rev. 2002, 102, 2357; b) K. Kuriki, Y. Koike, Y. Okamoto, Chem. Rev. 2002, 102, 2347; c) P. Caravan, Chem. Soc. Rev. 2006, 35, 512; d) S. P. Fricker, Chem. Soc. Rev. 2006, 35, 524; e) B. M. van der Ende, L. Aarts, A. Meijerink, Phys. Chem. Chem. Phys. 2009, 11, 11081; f) S. V. Eliseeva, J.-C. G. Bünzli, Chem. Soc. Rev. 2010, 39, 189.

[4] https://www.sciencedirect.com/handbook/handbook-on-the-physics-andchemistry-of-rare-earths

[5] a) M. E. Weeks, 'The Discovery of the Elements', 7th Ed., J. Chem. Educ. Publishers, Easton, 1968; b) J. W. van Spronsen, 'The Periodic System of the Elements', Elsevier, Amsterdam, 1969; c) E. R. Scerri, 'The Periodic Table, Its Story and Its Significance', Oxford University Press, New York, 2007

[6] W. Crookes, J. Chem. Soc. 1888, 53, 487.

[7] M. Fontani, M. Costa, M. V. Orna, 'The Lost Elements', Oxford University Press, New York, 2015, pp 119-127.

[8] C. K. Jorgensen, in 'Handbook on the Physics and Chemistry of Rare Earths', Eds. K. A. Gschneidner Jr, L. Eyring, Elsevier, 1988, 11, pp 197-287. The subtle different nomenclatures used for lanthanoids ( $\mathrm{La}-\mathrm{Lu}$ ) and lanthanides $(\mathrm{Ce}-\mathrm{Lu})$ are not considered in this broad scope mini-review. Only the most popular term 'lanthanide' is used throughout the text.

[9] a) H. G. Friedman Jr, G. R. Choppin, D. G. Feuerbacher, J. Chem. Educ. 1964, 41, 354; b) E. Morenao-Pineda, L. E. Nodaraki, F. Tuna in 'Novel Magnetic Nanostructures', Eds. N. Domracheva, M. Caporali, E. Rentschler, Elsevier, 2018, pp 1-50.

[10] J. C. Slater, Phys. Rev. 1930, 36, 57

[11] N. Kaltsoyannis, P. Scott, 'The f-Elements', Oxford Science Publications, Oxford, 1999.

[12] D. A. Johnson, 'Some Thermodynamic Aspects of Inorganic Chemistry', 2nd Ed., Cambridge University Press, Cambridge, 1982, pp 154-163.

[13] D. H. Woen, W. J. Evans in 'Handbook on the Physics and Chemistry of Rare Earths', Eds. J.-C. G. Bünzli, V. K. Pecharsky, Elsevier Science, Amsterdam, 2016, 50, pp 337-394.

[14] C.-G. Ma, M. G. Brik, D.-X. Liu, B. Feng, Y. Tian, A. Suchocki, J. Luminesc. 2016, 170,369

[15] C. Görller-Walrand, K. Binnemans in 'Handbook on the Physics and Chemistry of Rare Earths', Eds. K. A. Gschneidner Jr, L. Eyring, Elsevier Science, Amsterdam, 1996, 23, pp 121-283.

[16] a) C. Görller-Walrand, K. Binnemans in 'Handbook on the Physics and Chemistry of Rare Earths', Eds. K. A. Gschneidner Jr, L. Eyring, Elsevier Science, Amsterdam, 1998, 25, pp 101-264; b) M. P. Helhen, M. G. Brik, K. W. Krämer, J. Luminesc. 2013, 136, 221.

[17] C. K. Jorgensen, Structure and Bonding 1981, 43, 1.

[18] a) S. V. Eliseeva, J.-C. G. Bünzli, New J. Chem. 2011, 35, 1165.

[19] J.-C. G. Bünzli in 'Handbook on the Physics and Chemistry of Rare Earths', Eds.: J.-C. G. Bünzli. V. K. Pecharsky, Elsevier Science, Amsterdam, 2016, 50, pp 141-176.
[20] T. Moeller, 'Advances in Chemistry, Werner Centennial', Ed. G. B. Kaufmann, American Chemical Society, Washington, 1967, pp 306-317.

[21] E. C. Constable, C. E. Housecroft, Chem. Soc. Rev. 2013, 42, 1429.

[22] G. Urbain, Bull. Soc. Chim. Paris 1896, 15, 347.

[23] a) J. A. A. Ketelaar, Physica 1937, 4, 619; b) L. Helmholz, J. Am. Chem. Soc. 1939, 61, 1544.

[24] a) G. Schwarzenbach, 'Complexometric Titrations', Chapman \& Hall: London, 1957; b) G. Anderegg, P. Nägeli, F. Müller, G. Schwarzenbach, Helv. Chim. Acta 1959, 42, 827; c) G. Anderegg, Helv. Chim. Acta 1960, 43, 825.

[25] M. D. Lind, B. Lee, J. L. Hoard, J. Am. Chem. Soc. 1965, 87, 1611.

[26] J. L. Hoard, B. Lee, M. D. Lind, J. Am. Chem. Soc. 1965, 87, 1612.

[27] 'Rare Earth Coordination Chemistry', Ed. C. Huang, John Wiley \& Sons, Singapore, 2010.

[28] A. F. Williams, C. Piguet, G. Bernardinelli, Angew. Chem. Int. Ed. Engl. 1991, 30, 1490.

[29] P. Chen, H. Li, W. Sun, J. Tang, L. Zhang, P. Yan, CrystEngComm 2015, 17, 7227.

[30] C. O. Dietrich-Buchecker, J. Guilhem, C. Pascard, J.-P. Sauvage, Angew. Chem. Int. Ed. Engl. 1990, 29, 1154.

[31] G. Zhang, G. Gil-Ramirez, A. Markevicius, C. Browne, I. J. VitoricaYrezabal, D. A. Leigh, J. Am. Chem. Soc. 2015, 137, 10437.

[32] T. H. Maiman, Nature 1960, 187, 493.

[33] a) R. Reisfeld, C. K. Jorgensen, 'Lasers and Excited States of Rare Earths', Springer-Verlag, Berlin Heidelberg, New York, 1977; b) 'Spectroscopic Properties of Rare Earths in Optical Materials', Eds. G. Liu, B. Jacquier, Springer-Verlag, Berlin Heidelberg, 2005.

[34] M. Goeppert-Mayer, Ann. Phys. 1931, 401, 273.

[35] P. A. Franken, A. E. Hill, C. W. Peters, G. Weinreich, Phys. Rev. Lett. 1961, 7, 118

[36] W. Kaiser, C. G. B. Garrett, Phys. Rev. Lett. 1961, 7, 229.

[37] F. Auzel, C. R. Acad. Sc. Paris 1966, B262, 1016.

[38] F. Auzel, Chem. Rev. 2004, 104, 139.

[39] a) J. Zhou, Q. Liu, W. Feng, Y. Sun, F. Li, Chem. Rev. 2015, 115, 395; b) X.-Y. Wang, R. R. Valiev, T. Y. Ohulchanskyy, H. Agren, C. Yang, G. Chen, Chem. Soc. Rev. 2017, 46, 4150; J. Zhou, J. L. Leano Jr., Z. Liu, K.-L. Wong, R.-S. Liu, J.-C. G. Bünzli, Small 2018, 1801882.

[40] a) X. Huang, S. Han, W. Huang, X. Liu, Chem. Soc. Rev. 2013, 42, 173; b) J.C. G. Bünzli, A.-S. Chauvin, in 'Handbook on the Physics and Chemistry of Rare Earths', Eds.: J.-C. G. Bünzli, V. K. Pecharsky, Elsevier North Holland, Amsterdam 2014, 44, pp 169-281.

[41] J. Luzon, R. Sessoli, Dalton Trans. 2012, 41, 13556.

[42] J. D. Rinehart, J. R. Long, Chem. Sci. 2011, 2, 2078.

[43] a) R. Sessoli, H. L. Tsai, A. R. Schake, S. Wang, J. B. Vincent, K. Folting, D. Gatteschi, G. Christou, D. N Hendrickson, J. Am. Chem. Soc. 1993, 115, 1804; b) L. Sorace, C. Benelli, D. Gatteschi, Chem. Soc. Rev. 2011, 40, 3092

[44] a) N. Ishikawa, M. Sugita, T. Ishikawa, S.-Y. Koshihara, Y. Kaizu, J. Am. Chem. Soc. 2003, 125, 8694; b) N. Ishikawa, J. Phys. Chem. A 2003, 107, 5831 ; c) N. Ishikawa, M. Sugita, T. Okubo, N. Tanaka, T. Iino, Y. Kaizu, Inorg. Chem. 2003, 42, 2440.

[45] a) R. Clérac, R. E. P. Winpenny, Structure and Bonding 2016, 172, 35; b) S. G. McAdams, A.-M. Ariciu, A. K. Kostopoulos, J. P. S. Walsh, F. Tuna, Coord. Chem. Rev. 2017, 346, 216; c) S. K. Gupta, R. Murugavel, Chem. Commun. 2018, 54, 3685.

[46] Z.-N. Chen, J. Rare Earth 2011, 29, 1.

[47] K. Majcher, MIT Technology Review, 2015 https://www.technologyreview. $\mathrm{com} / \mathrm{s} / 535381 /$ what-happened-to-the-rare-earths-crisis/

[48] a) C. Piguet, J.-C. G. Bünzli, B. Donnio, D. Guillon, Chem. Commun. 2006, 3755; b) K. Binnemans, in 'Handbook on the Physics and Chemistry of Rare Earths', Eds. J.-C. G. Bünzli, V. K. Pecharsky, Elsevier Science, Amsterdam, 2013, 43, pp 1-158; c) S. Guerra, T. Dutronc, E. Terazzi, K. Buchwalder, L. Guénée, R. Deschenaux, S. V. Eliseeva, S. Petoud, C. Piguet, Coord. Chem. Rev. 2017, 340, 79.

[49] a) K. Binnemans, Chem. Rev. 2009, 109, 4283; b) J. Feng, H. Zhang, Chem. Soc. Rev. 2013, 42, 387.

[50] a) M. Haase, H. Schäfer, Angew. Chem. Int. Ed. 2011, 50, 5808; b) G. Chen, C. Yang, P. N. Prasad, Acc. Chem. Res. 2013, 46, 1474; c) S. Gai, C. Li, P. Yang, J. Lin, Chem. Rev. 2014, 114, 2343.

[51] a) J. M. Stanley, B. J. Holliday, Coord. Chem. Rev. 2012, 256, 1520; b) O. Guillou, C. Daiguebonne, G. Calvez, K. Bernot, Acc. Chem. Res. 2016, 49 , 844; c) A. Winter, U. S. Schubert, Chem. Soc. Rev. 2016, 45, 5311; d) L. Babel, K. Baudet, T. N. Y. Hoang, H. Nozary, C. Piguet, Chem. Eur. J. 2018, 24,5423 .

[52] a) 'Lanthanides: Chemistry and Use in Organic Synthesis', in 'Topics in Organometallic Chemistry', Ed. S. Kobayashi, Springer-Verlag, Berlin Heidelberg, New York, 1999, 2, pp 1-305; b) P. G. Steel, J. Chem. Soc. Perkin Trans. 1 2001, 2727; c) M. Shibasaki, M. Kanai, S. Matsunaga, N. Kumagai, Acc. Chem. Res. 2009, 42, 1117.

[53] a) L.-D. Sun, Y.-F. Wang, C.-H. Yan, Acc. Chem. Res. 2014, 47, 1001; b) M C. Heffern, L. M. Matosziuk, T. J. Meade, Chem. Rev. 2014, 114, 4496; c) M. Sy, A. Nonat, N. Hildebrandt, L. J. Charbonnière, Chem. Commun. 2016 52,5080 .

[54] J.-C. G. Bünzli, Nat. Nanotechnol. 2018, DOI 10.1038/s41565-018-0249-1. 